\title{
TEATRO DE SOMBRAS NA EDUCAÇÃO INFANTIL, NA CONTEMPORANEIDADE: VIVÊNCIAS NO USO DE TELAS MÓVEIS
}

DOI: http://dx.doi.org/10.5965/198431781112015145

Ana Lucia Kroeff Vieira ${ }^{1}$

\section{RESUMO}

$\mathrm{O}$ artigo apresenta um estudo desenvolvido em experiências no ensino de teatro na educação infantil, realizado a partir do Programa Institucional de Iniciação a Docência - PIBID, da Coordenação de Aperfeiçoamento de Pessoal de Ensino Superior - CAPES, no curso de Licenciatura em Teatro, na Universidade do Estado de Santa Catarina, em 2014. No projeto atuei como professora em um grupo de crianças no Núcleo de Desenvolvimento Infantil, da Universidade Federal de Santa Catarina, e durante os encontros abordei o uso de elementos da linguagem do teatro de sombras na contemporaneidade, como telas móveis e lanternas, em momentos de brincadeira, aprendizagem e apreciação da linguagem teatral. A ação metodológica teve como foco possibilitar a reflexão sobre os aspectos teatrais no ensino de teatro com crianças, assim questionando a necessidade da apresentação de uma peça teatral no ensino na educação infantil.

Palavras-chave: Ensino de teatro. Educação infantil. Teatro de sombras. Aspectos teatrais.

\begin{abstract}
The article presents one study developed in experiences in teaching Theatre in early childhood education, held from the Institutional Program of Initiation to Teaching-PIBID, the CAPES Staff Development Coordination of higher education, in the course of degree in Theater at the University of the State of Santa Catarina, in 2014. In the Project, I worked as a teacher in a group of children in the child development center, Federal University of Santa Catarina and I used the elements of the language of the shadows theatre in contemporary times, as mobile screens and flashlights, in moments of joking, learning and appreciation of theatrical language with childrens. The action methodology focused enable reflection on theatrical aspects in teaching Theatre with childrens, thus questioning the necessity of presenting a play with the kids in the early childhood education.
\end{abstract}

Keywords: Teaching Theatre. Early childhood education. Shadows theatre. Theatrical aspects.

\footnotetext{
${ }^{1}$ Graduanda na Licenciatura em Artes Visuais. Universidade do Estado de Santa Catarina.
} 


\section{EDUCAÇÃO, ARTES}

\section{Introdução}

Neste artigo, desenvolvo reflexões a partir da descrição de experiências vivenciadas como docente no ensino de teatro para a educação básica, proporcionadas pelo curso de Licenciatura em Teatro, através do Programa de Iniciação à Docência da CAPES, na UDESC, em Florianópolis. Em 2014, o projeto contemplou a etapa da educação infantil no Núcleo de Desenvolvimento Infantil da Universidade Federal de Santa Catarina, embora já tenha a atuação de alunos, iniciando a docência na área de teatro, em outras etapas da educação básica em uma escola do município. Foram seis bolsistas que atuaram no NDI-Núcleo de Desenvolvimento Infantil, desenvolvendo suas práticas pedagógicas em duplas, com grupos de crianças de faixas etárias distintas, com a supervisão da professora de Artes Vania Maria Broering e sob a coordenação do projeto na UDESC, do Prof. Dr. Vicente Concílio. Estive participando do projeto no decorrer dos dois semestres de 2014. No início do ano, atuei como docente no grupo que teve a professora Soraya Franzoni Conde como responsável. O seu planejamento de ensino partiu da temática: o sistema solar, para as abordagens e vivências. Eram 17 crianças com idade entre 5 e 6 anos.

Por considerar que o brincar das crianças deve ser preservado no ensino na educação infantil, o questionamento propulsor ao meu estudo foi com relação a apresentação teatral: como sustentar o caráter lúdico nas vivências com as crianças? O autor e pedagogo Peter Slade (1978) ressalta que é preciso saber distinguir o jogo dramático infantil do fazer teatro entendido pelo adulto, pois neste último há quem faz algo: os atores, para quem assiste: o público. Sobre o jogo dramático infantil o autor afirma que é o comportamento vital da criança, a maneira dela pensar, lembrar, criar, experimentar, comprovar, absorver, relaxar, assim para ela "enquanto ainda ilibada (...) particularmente nos primeiros anos - cada pessoa é tanto ator como auditório" (p.18). Portanto, o estudo que realizei teve como foco a linguagem do teatro de sombras na perspectiva contemporânea, que explora as possibilidades de uso dos elementos: tela, luz e silhuetas, para a criação e comunicação de uma história. Assim, foram propiciadas às crianças vivências do fazer teatro de sombras possibilitando interações no grupo por meio de telas móveis, do uso de lanternas e da manipulação de 


\section{EDUCAÇÃO, ARTES}

VOLUME 11, NÚMERO 1, Ano 2015

E INCLUSÃO

ISSN 1984-3178

silhuetas, e a consequente aprendizagem da linguagem teatral. Com isto, foi enfatizado o processo de ensino sem se deter a condução de uma apresentação.

Neste artigo, descrevo algumas das práticas realizadas e as reflexões que permearam a minha experiência como professora no grupo, com o intuito de possibilitar à reflexão sobre aspectos teatrais a serem considerados no ensino na educação infantil.

\section{A linguagem do teatro de sombras}

O teatro de sombras é um modo de fazer teatro que se aproxima muito da fantasia, do imaginário, do faz-de-conta de uma criança. Ver uma sombra como uma imagem sendo desenhada e perceber como ela se cria e conta algo, aguça sensações e a imaginação de quem está fazendo e vendo.

No início das manhãs, no Núcleo de Desenvolvimento Infantil na UFSC, as crianças têm um momento preservado para brincar quando chegam na sala, no seu grupo. Logo se reúnem em roda com a professora, que conversa com elas sobre as atividades do dia. Em um destes momentos, mostramos ao grupo o material que íamos usar nos próximos encontros e que é utilizado para fazer teatro de sombras. O material consistia em lanternas pequenas, uma tela construída com um tecido costurado em uma base de bambolê e pequenos objetos de uso no cotidiano das crianças nas brincadeiras em sala: bonecos pequenos de plástico, vestimentas de bonecos, peças de brinquedos de madeira (ver Figura 01). Para isso, organizamos o espaço onde é feita a roda das crianças na sala: usamos tecidos como cortinas, para delimitá-lo e bloquear a passagem da luminosidade da sala, e colocamos os objetos e as lanternas acesas dentro de uma cesta fechada no centro da roda, junto da tela de bambolê. Ao chegarem na sala, as crianças ficaram curiosas para saber o que íamos fazer e o que tinha dentro da cesta. "É um espelho mágico" - disse uma delas vendo a tela. "E o que será que a gente pode ver através de um espelho mágico?" - perguntamos. Logo elas quiseram usar as lanternas, e mostramos a elas como modificar as imagens das sombras dependendo da aproximação do objeto entre a tela e a luz da lanterna. 

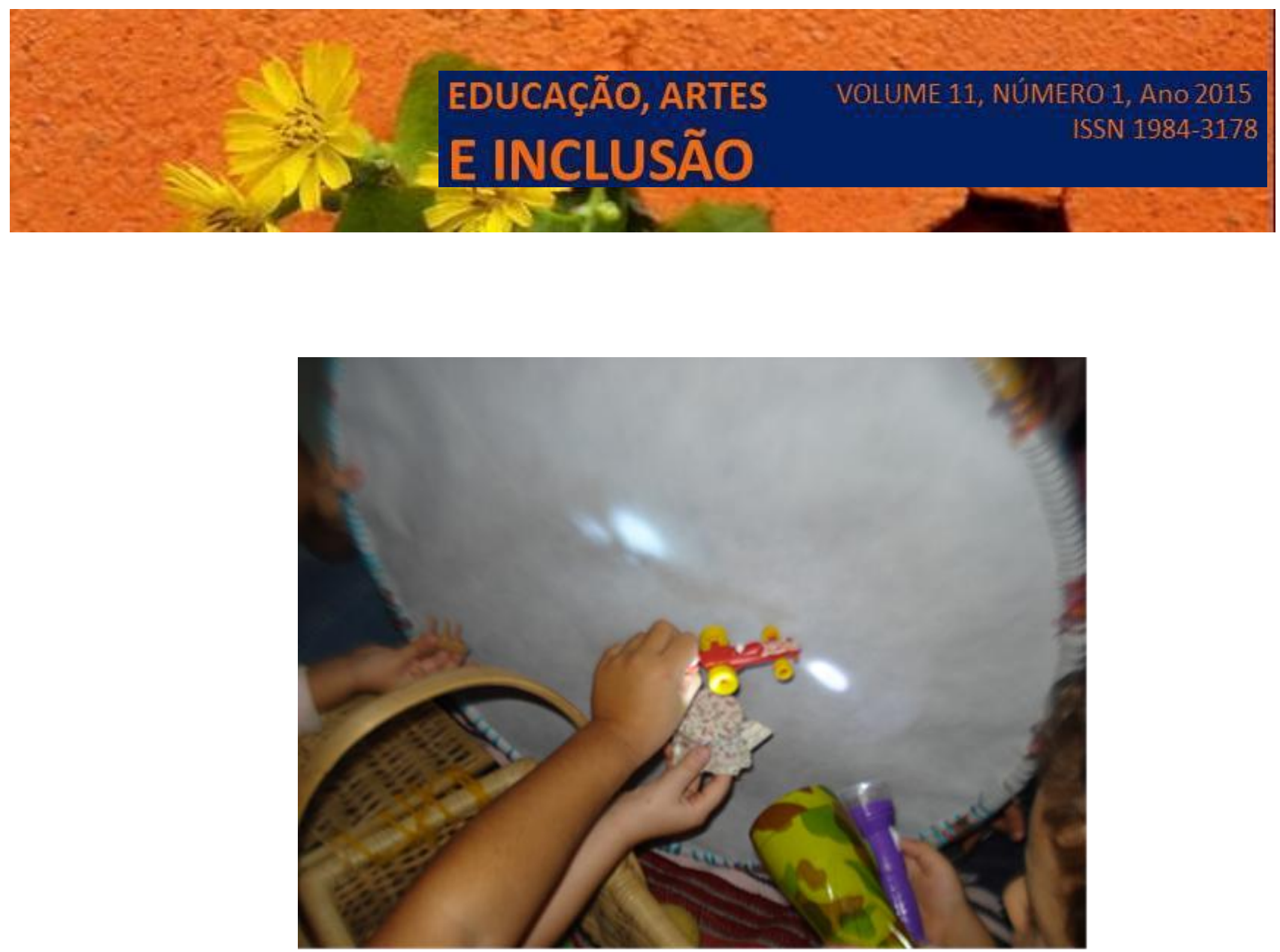

Figura 1 - Tela e objetos

Outro dia, levamos para a sala alguns bambolês e objetos menores, também com o formato de uma circunferência, para construir junto com as crianças outras telas usando tecido e lãs coloridas para a costura (ver Figura 2). Algumas quiseram logo costurar, outras preferiram usar as lanternas.

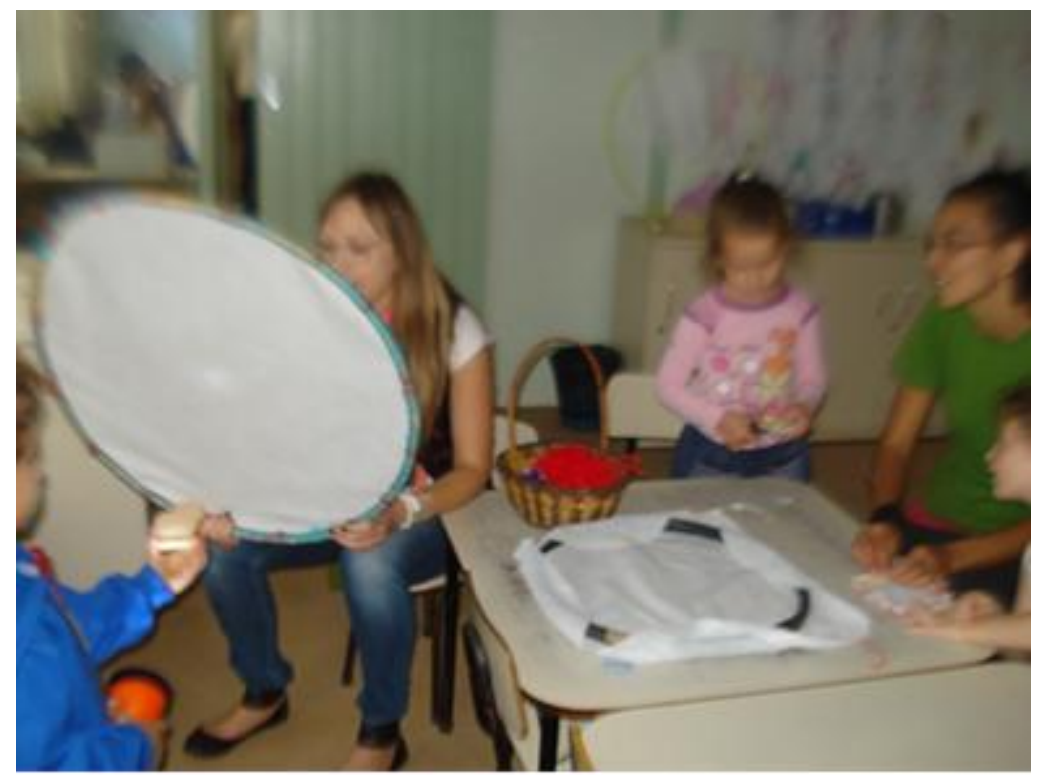

Figura 2 - Construção das telas 


\section{EDUCAÇÃO, ARTES E INCLUSÃO}

VOLUME 11, NÚMERO 1, Ano 2015

Um dos meninos maiores do grupo levou uma das telas ao corredor e começou a jogála no ar como um disco (ver Figura 3). Outras crianças se aproximaram, e ficaram surpresas ao vê-la demorar a cair ou quando seguia para outra direção. Elas também brincaram com outros objetos no corredor (ver Figura 4). A última atividade da manhã foi a brincadeira no parque de jogar os "discos". Uma criança arremessava no grupo e todas iam correndo na direção que o disco ia, para pegá-lo.

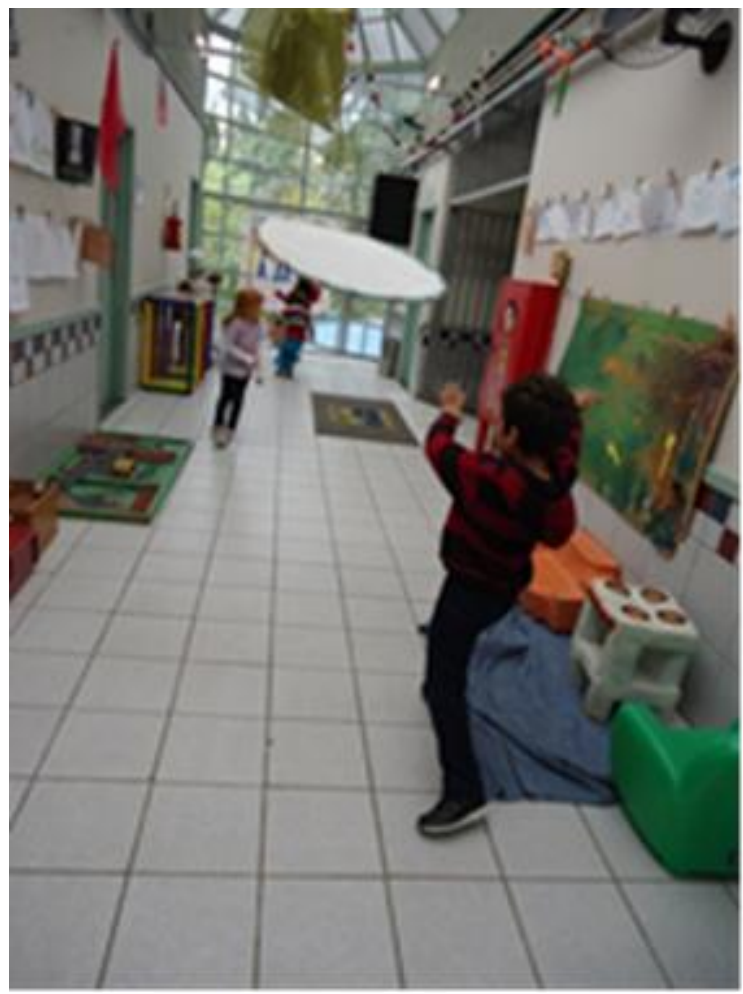

Figura 3 - Tela disco 


\section{EDUCAÇÃO, ARTES

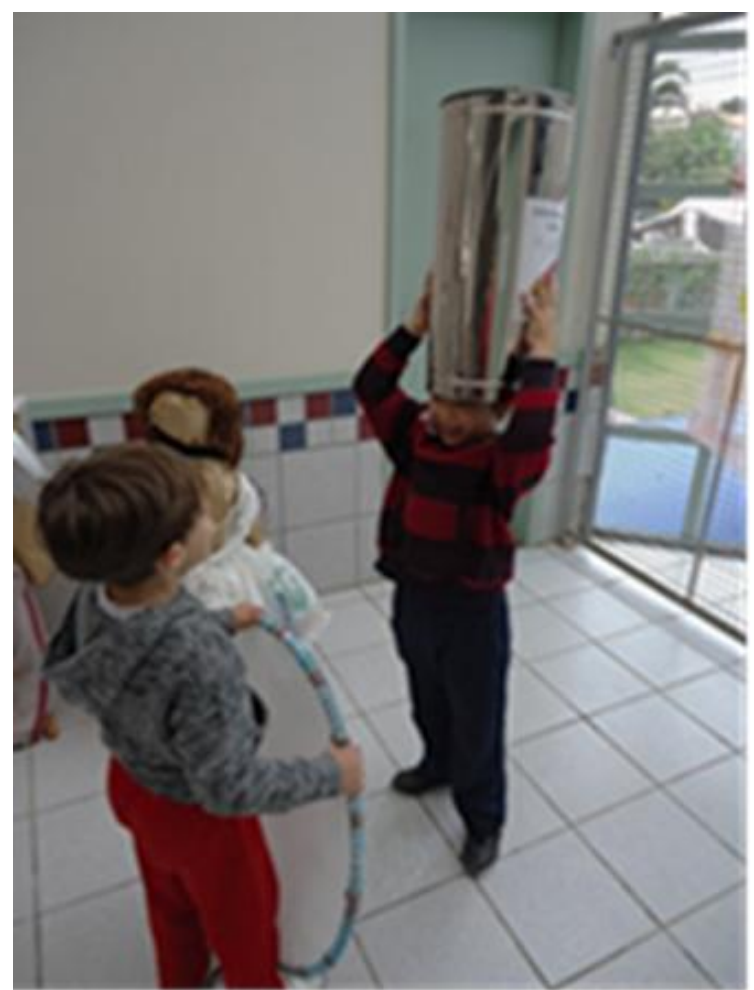

Figura 4 - Brincadeiras no corredor

A autora Marina Marcondes, pesquisadora na área da pedagogia do teatro na contemporaneidade, enfatiza em seus estudos a importância do adulto em compartilhar momentos junto com a criança, em olhar e conviver com ela na maneira em que ela se expõe no mundo, em tempos em que o convívio tem sido substituído pela indústria cultural que dita o que é próprio para as crianças. Marcondes (2014) comenta que "reside no brincar, especialmente no brincar imaginativo as sementes da teatralidade" (p.8), e ressalta que "a cada noção de infância e criança corresponde um modo de ser, estar e agir da comunidade adulta - bem como a um modo relacional no mundo compartilhado, entre adultos e crianças e, portanto, corresponde também a um jeito de produzir e ensinar teatro" (p.4).

Observei em muitos momentos que as crianças brincam com a forma dos objetos que exploram usando a imaginação, assim facilmente elas transformam os fazeres em brincadeiras e contam histórias. As lãs coloridas viraram pulseiras a pedido de algumas. Nestes primeiros momentos de integração no grupo com o material, pude observar a aproximação delas e suas relações em grupo. Penso na importância de construir uma relação de amizade e confiança com as crianças desde o início de um trabalho como professora. Conforme o pensamento do 


\section{EDUCAÇÃO, ARTES

autor Peter Slade (1978), "a melhor brincadeira teatral infantil só tem lugar onde oportunidade e encorajamento lhe são conscientemente oferecidos por uma mente adulta" (p.18).

Em outro encontro fomos com as crianças no auditório do NDI, para assistirmos dois filmes ${ }^{2}$ com atores criando imagens em sombras de maneiras distintas (ver Figura 5). Depois de assistirmos, conversamos com elas sobre como tinham sido feitas as sombras: no primeiro filme usaram as mãos e os dedos e no segundo máscaras feitas com papel recortado, tecidos, e desenhos em transparências. Algumas crianças dançaram desde o início dos filmes ao ouvir as músicas, então sugerimos ao grupo um momento para todas dançarem, somente ouvindo as músicas. Assim, iniciamos os filmes novamente.

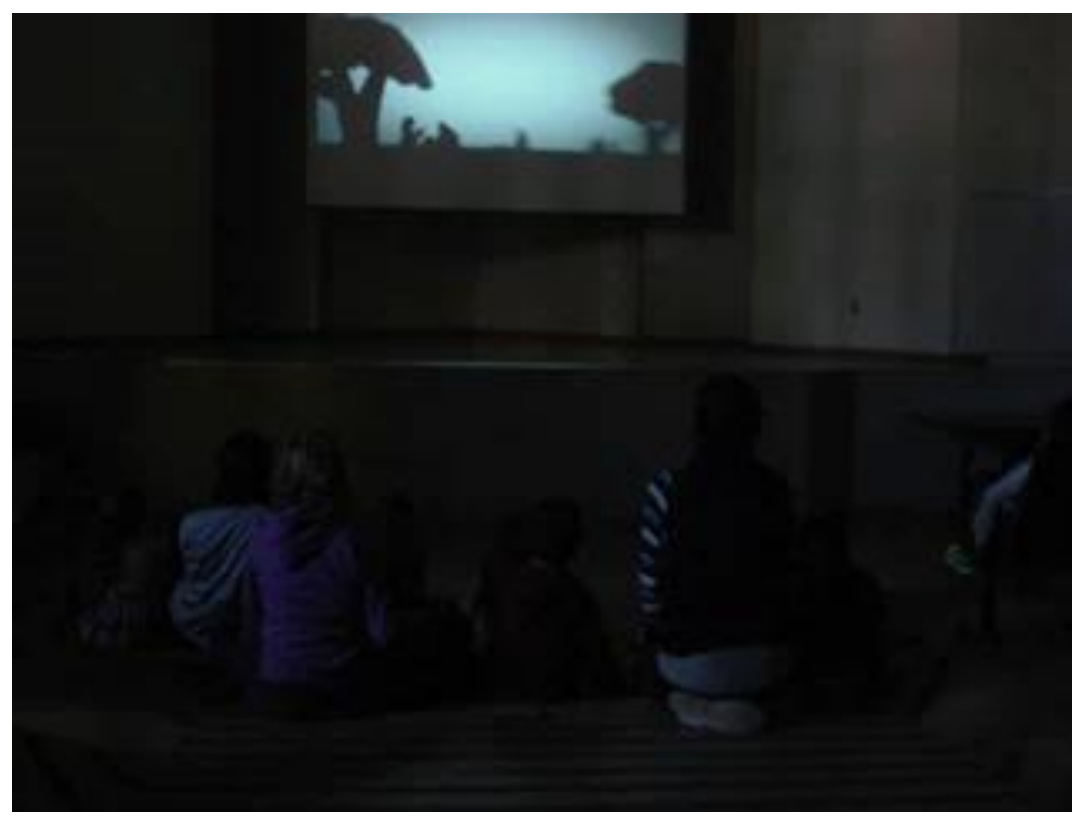

Figura 5 - Filme no auditório

O grupo logo se espalhou em frente ao palco do auditório e iniciaram as suas danças (ver Figura 6). Uma delas sugeriu que a brincadeira fosse de estátua, assim toda vez que era diminuído o som da música, elas paravam o movimento ficando em posições de estátua. Sobre o jogo dramático da criança, Slade (1978) comenta que:

Pode haver momentos intensos do que poderíamos nos dignar a chamar de teatro, mas no geral trata-se de drama, e a aventura, onde o fazer, o buscar e o lutar são tentados por todos. Todos são fazedores tanto ator como público [...] A ação tem lugar por toda parte em volta de nós e não existe a questão de quem deve representar

2 Priyanka Rungta, direção e produção: https://www.youtube.com/watch?v=e81f8ThHaLs e Cia Soldenoche: http://soldenocheteatro.blogspot.com.br/2013/01/fatima-la-hilandera.html 


\section{EDUCAÇÃO, ARTES

para quem e quem deve ficar sentado vendo quem fazendo o quê! E nesse drama notam-se duas qualidades importantes: absorção e sinceridade. Absorção - estar absorto - é estar totalmente envolvido no que está sendo feito, ou no que se está fazendo, com exclusão de quaisquer outros pensamentos, incluindo a percepção ou o desejo de um auditório. Sinceridade é uma forma completa de honestidade ao representar um papel, trazendo consigo um sentimento intenso de realidade e experiência [...]. (SLADE, 1978, p.18)

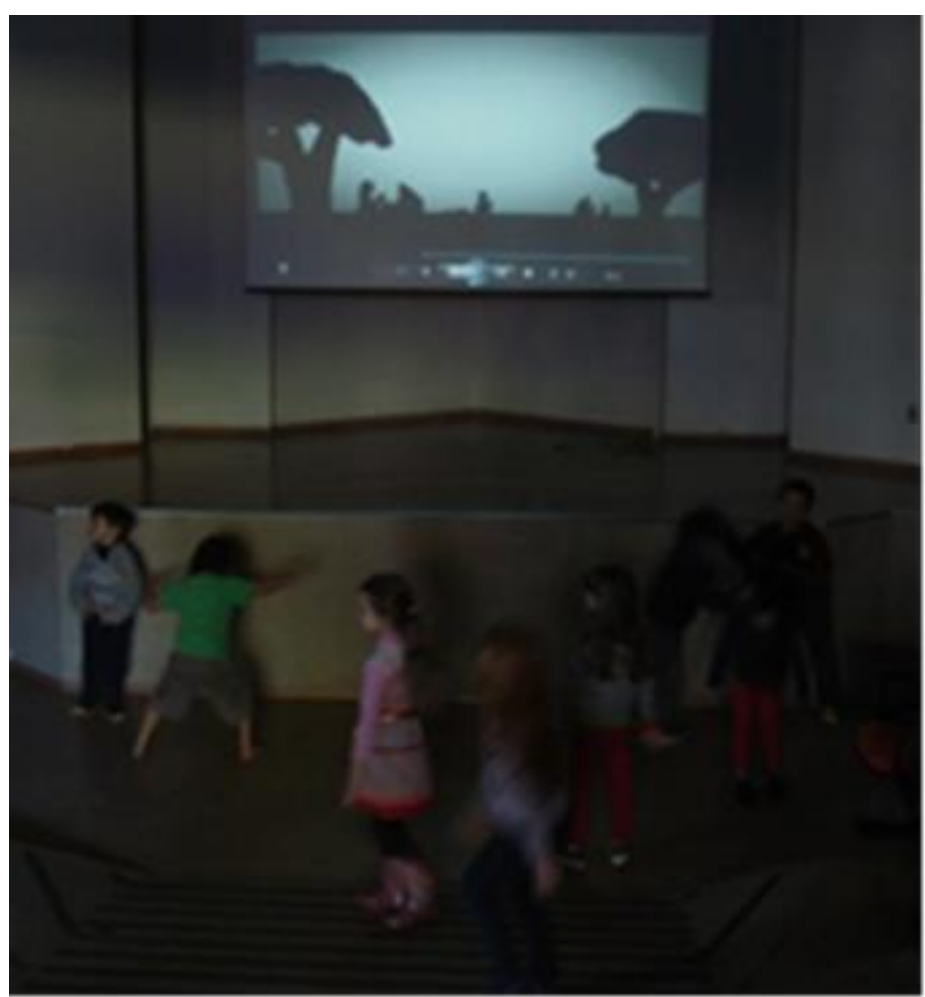

Figura 6 - Crianças dançando

O autor ressalta a importância destas qualidades ao drama das crianças e afirma que ele pode se distinguir em: jogo pessoal, que se "caracteriza por movimento e caracterização, e notamos a dança entrando e a experiência de ser coisas ou pessoas" (p.19), e em jogo projetado, que "é o drama no qual é usada a mente toda, mas o corpo não é usado tão totalmente" (p.19). O jogo projetado se aproxima do brincar das crianças com bonecos e objetos "que ou assumem caracteres da mente ou se tornam parte do local [palco no sentido teatral] onde o drama acontece" (p.19).

De acordo com a observação de Marina Marcondes (2014) "uma atmosfera relacional brincante leva a criança a um estado, uma qualidade, uma presença que muitas vezes a 


\section{EDUCAÇÃO, ARTES}

VOLUME 11, NÚMERO 1, Ano 2015 E INCLUSÃO

situação palco-plateia não dá conta” (p.8). A autora (2010), que tem seus estudos centrados na fenomenologia da infância, comenta que as experiências das crianças são distintas das nossas devido as características próprias da primeira infância, definidas pelo filósofo Merleau-Ponty: "sua maneira de viver o mundo é não-representacional; ela transita entre realidade e imaginação na sua vida cotidiana, tal como nós em sonho, sem problemas; e seu pensamento é polimorfo, pré-lógico" (p.119). Assim ela considera que é preciso rever o olhar sobre as crianças "pois se a criança pequena não é de nenhum modo representacional, também outras vias de acesso à sua maneira de ser, tais como sua corporalidade, brincadeiras e dizeres, devem ser revistas [...] (MARCONDES, 2010,p.129)

\section{A casa das sombras}

No final de cada semestre no NDI, são expostos os trabalhos realizados nos grupos para compartilhar entre as professoras, entre as crianças, e com os familiares. Instalamos as telas móveis dentro da casinha de madeira, que as crianças brincam no pátio. $\mathrm{O}$ espaço foi organizado de maneira que as crianças pudessem interagir com os objetos e entre elas. (ver Figura 7). No centro da casinha penduramos a tela bambolê maior e deixamos uma lanterna acesa fixa no alto para iluminá-la. Instalamos as telas menores ocupando outros espaços nos cantos da casinha e próximas de cadeiras e almofadas para as crianças se acomodarem. Escolhemos objetos no berçário, brinquedos pequenos como: animais de borracha, personagens de desenhos animados de plástico, letras em EVA, bolas, entre outros, que ficaram dentro de cestas para as crianças escolherem o brinquedo. Como tinham poucas lanternas, cada grupo que visitava a casinha as recebia com a condição de emprestá-las no grupo, assim alternando entre quem iluminava e quem assistia. Uma das crianças nomeou: "a casa das sombras!"’. Nós permanecemos dentro da casinha orientando-as, pois tinham que usar a lanterna com uma das mãos para iluminar o objeto e com a outra segurá-lo e ver a sombra que se projetava na tela. 

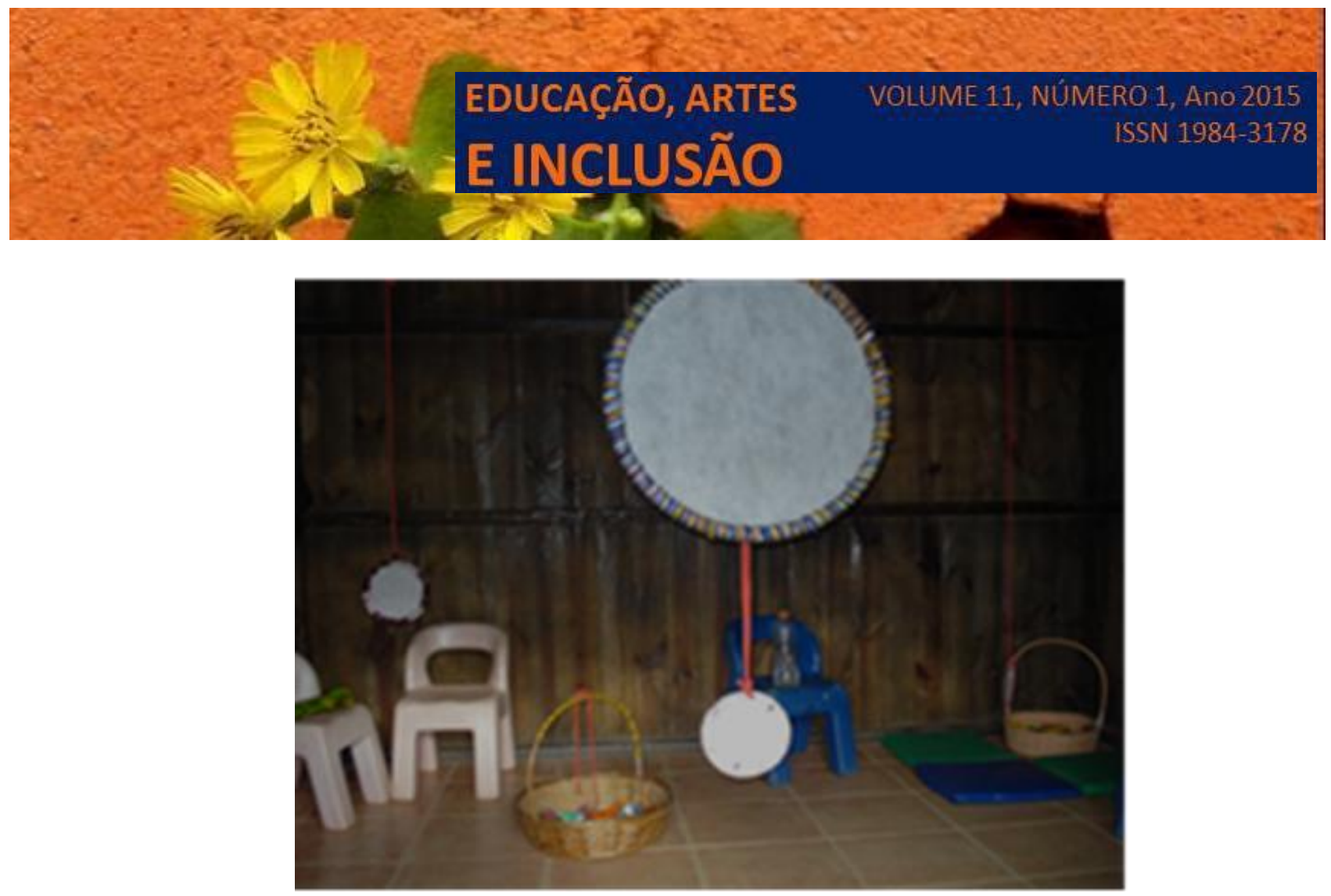

Figura 7 - Telas instaladas dentro da casinha

Algumas crianças maiores exploraram mais a movimentação das lanternas, vendo a sombra aumentar na tela quando aproximava a lanterna do objeto, assim modificando as formas das sombras (ver Figura 8). Outras brincaram com as lanternas vendo as sombras pelas paredes da casa e quando iluminavam os outros. Algumas abriam os panos das janelas e da entrada da casa deixando a luz passar e fechavam novamente.

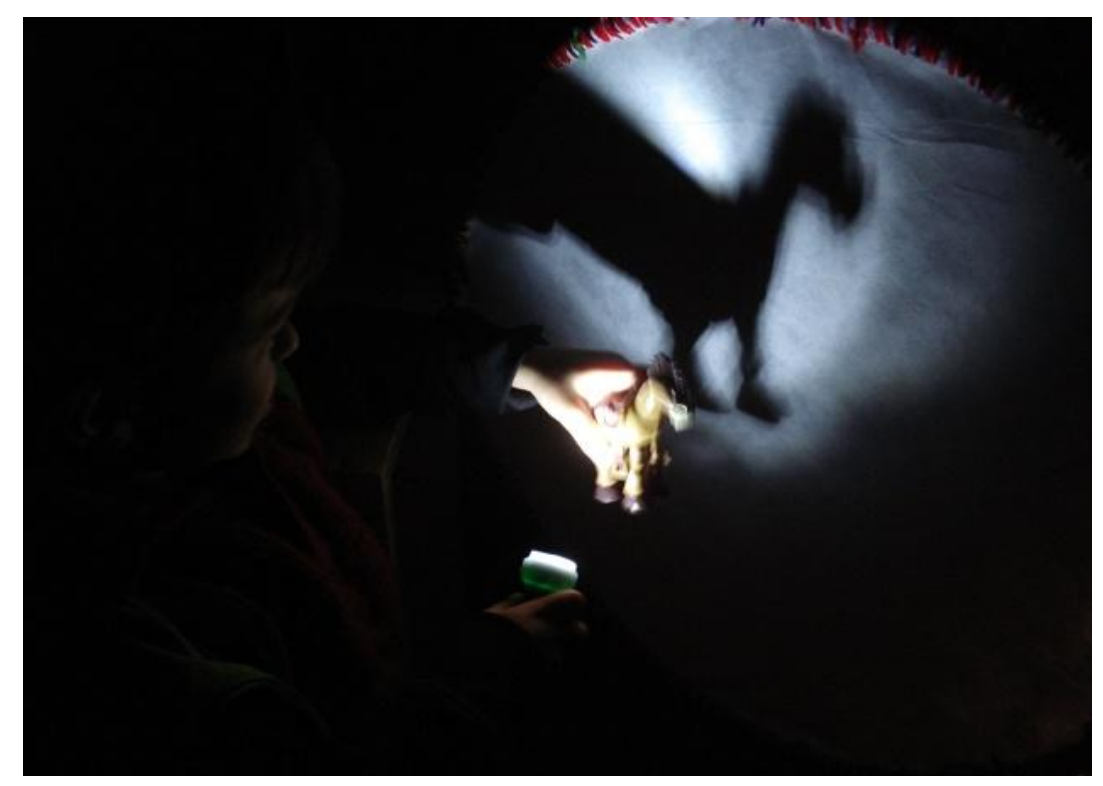

Figura 8 - Menino vendo a sombra aumentar 


\section{EDUCAÇÃO, ARTES

As crianças menores, com dois e três anos, ficaram muito entusiasmadas ao entrar, mas a atenção delas se voltou mais aos objetos do que às sombras nas telas, elas queriam tocar em tudo o que estava ao alcance, e algumas não queriam largar o brinquedo. Elas gostavam de olhar para a luz na lanterna, então iluminavam várias partes na sala, no teto e no chão. Devido ao período curto de concentração das crianças nessa faixa etária, elas permaneceram menos tempo dentro da casinha. Alguns meninos preferiram apenas brincar com os brinquedos que escolhiam das cestas, usando as lanternas também (ver Figura 9). Duas meninas maiores, de um dos grupos quiseram ficar mais tempo dentro da casinha contando histórias e usavam a tela maior do centro. Conforme foram contando as histórias ${ }^{3}$, mais crianças retornaram e outras chegaram para assistir:

O dinossauro colocou um ovo e daí, nasceu um dinossauro. - menina

Sabia que os dinossauros nascem com sangue? - menina assistindo (...)

A galinha colocou um ovo e daí, deixou o ovo, e o monstro veio e comeu o ovo, e daí, sabe o que aconteceu? - menina

Que história mais sem graça, mas eu gostei! - outra menina assistindo

Ele tinha uma voz estranha, uma voz sabe de quê? Olha: piupiu, é um passarinho! menina

Figura 9 - Criança vendo os brinquedos

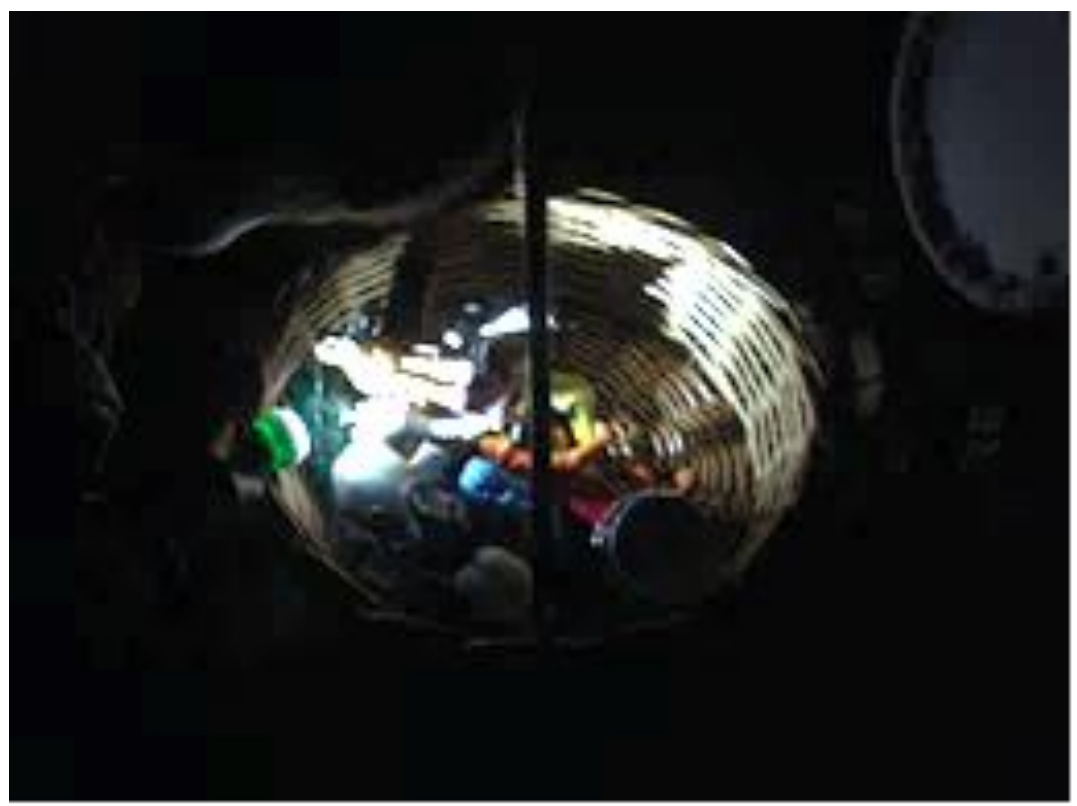




\section{EDUCAÇÃO, ARTES}

VOLUME 11, NÚMERO 1, Ano 2015

E INCLUSÃO

ISSN 1984-3178

Penso em uma aproximação do fazer teatro de sombras com o brincar da criança no jogo projetado. Neste, Slade (1978) afirma que "a tendência é para quietude mental e física. Os objetos com os quais se brinca, mais do que a pessoa que está brincando, criam vida e exercem a atuação, embora possa haver vigoroso uso da voz. O jogo projetado é o principal responsável pela crescente qualidade de absorção" (SLADE, 1978, p.19).

As qualidades: sinceridade e absorção, que o autor observou e ressaltou em seus estudos acompanhando o drama de crianças, também são importantes no trabalho do ator. Assim é possível observar aproximações do brincar da criança com o trabalho do ator e com o teatro entendido pelo adulto: como no teatro há a experiência emocional compartilhada entre o ator e a platéia, ocorre também no comportamento dramático da criança ao olhar de um adulto uma experiência compartilhada. Marina Marcondes (2014) define que o agachar do adulto para se aproximar da criança é uma atitude fenomenológica frente a elas e que essas atitudes são "maneiras de estar perto da criança mesma, compartilhando a capacidade humana da imaginação comungada em maneiras de brincar.” (MARCONDES, 2014, p.8)

Ao questionar o processo de ensino de teatro na educação infantil, penso na possibilidade de aproximação com a arte contemporânea para um espaço que enfatize a atuação das crianças, a presença lúdica, ao invés da representação de algo como usualmente o processo de ensino considera ao conduzir a uma apresentação. Segundo Bourriaud (2009) a obra contemporânea se apresenta "como uma duração a ser experimentada" (p.20) ao contrário dos ritmos e "durações que ordenam a vida cotidiana" (p.23). O autor afirma sobre a importância da arte contemporânea em problematizar a esfera das relações humanas ao considerar que "a mecanização geral das funções sociais reduz progressivamente o espaço relacional” (p.23) (BOURRIAUD, 2009, p.23). Assim penso que a arte contemporânea propicia outros encontros com as crianças, ampliando nossos olhares para além dos habituais a elas. 


\section{EDUCAÇÃO, ARTES}

VOLUME 11, NÚMERO 1, Ano 2015 E INCLUSÃO

\section{Jogo com silhuetas}

No segundo semestre ${ }^{4}$ a professora Juliane La Banca foi a responsável pelo grupo, que teve outro direcionamento nas atividades. Em um dos momentos que estive com as crianças, retomei a tela móvel de bambolê na sala e organizei um jogo com silhuetas, após a leitura da história de um livro ${ }^{5}$ no grupo. A história era sobre um menino que queria ter super poderes para resolver os seus problemas, mas no final ele percebe que não precisa desses poderes para resolvê-los. Durante a leitura as crianças viram as ilustrações da história e expressaram suas opiniões e percepções com o grupo:

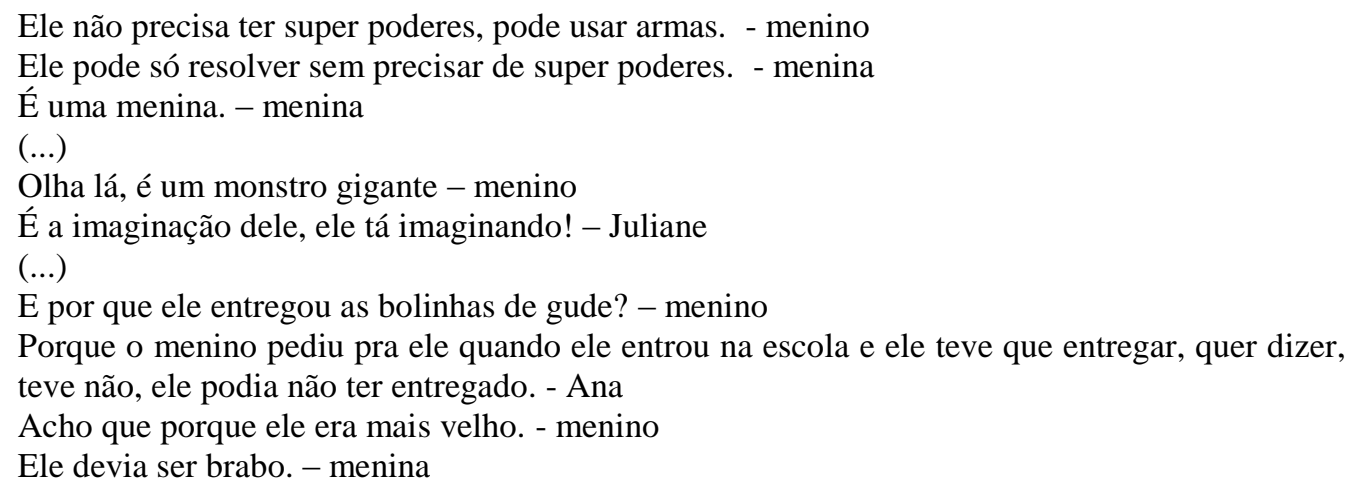

Cada criança pegou um dos envelopes que foi passado na roda, que continha uma silhueta com o formato do desenho de uma parte da história. Depois cada uma mostrou ao grupo a sua silhueta atrás da tela, que estava sendo iluminada. As demais crianças que estavam em frente a tela viam as sombras das silhuetas e assim tentavam adivinhar qual era a parte da história que o outro mostrava (ver Figura 10). Todas as crianças mostraram as silhuetas atrás da tela. Algumas lembraram da parte da história que correspondia a silhueta mostrada, e outras de outros momentos da história.

\footnotetext{
$4 \quad$ Inicialmente o grupo esteve envolvido em atividades com vista à apresentação na SEPEX - Semana de Pesquisa e Extensão da UFSC. Após o período que envolveu o evento, a professora teve como planejamento a criação de um livro com as crianças e a filmagem delas como personagens da história.
}

5 O livro tem como título: "Nícolas", dos autores: Agnés Laroche e Stéphanie Augusseau. 

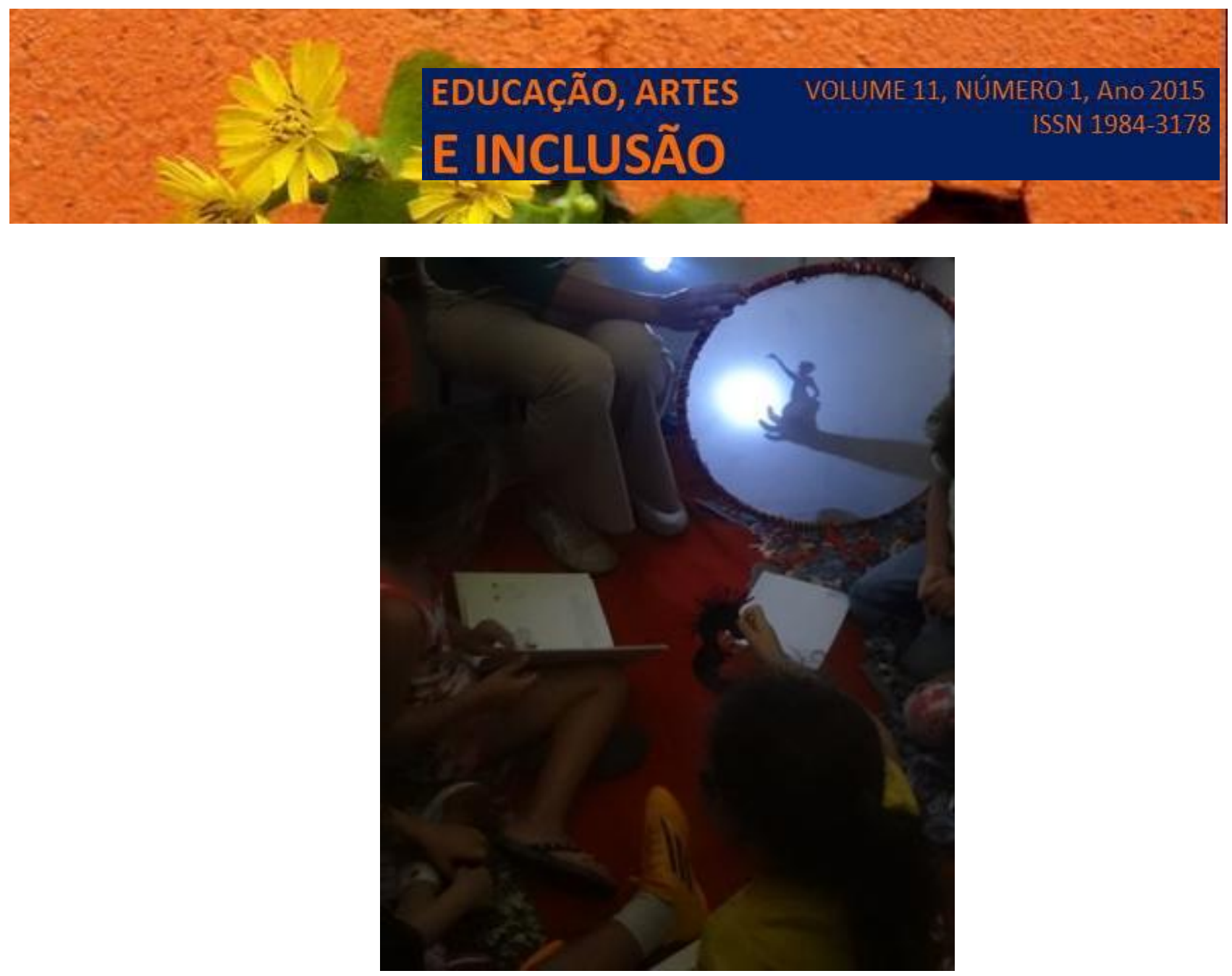

Figura 10 - Silhuetas, personagens da história

Devido ao curto espaço de tempo que tive para a atividade, levei as silhuetas prontas, mas procurei manter um padrão de tamanho ao fazê-las para distribuí-las entre as crianças (com intuito de evitar que elas comparassem entre si) e escolhi desenhos que significassem partes relevantes da história. Como o foco de atenção das crianças no jogo eram as silhuetas para lembrarem a história, penso que se estas tivessem sido feitas por cada criança, ao mostrálas haveria dispersão no grupo. No final do jogo, a maioria quis levar as silhuetas para a casa.

O jogo foi organizado a maneira de uma brincadeira em roda com as crianças na faixa etária em que frequentam a educação infantil. Com vista à manipulação das silhuetas pelas crianças, ele se assemelhou com o modo tradicional de fazer teatro de sombras nas escolas ${ }^{6}$, no entanto, teve o foco no coletivo e não na relação palco-platéia, onde é definido e separado no espaço quem apresenta e quem assiste (ver Figura 11). O uso da tela é um elemento que se distingue entre o teatro de sombras feito pelos ocidentais e orientais. Segundo Beltrame

$6 \quad$ Normalmente é realizado com a luz fixa no espaço e tela fixa sobre uma mesa, onde os alunos contam a história movimentando as silhuetas de desenhos por trás de uma tela e o professor tem em vista a apresentação como início ou finalização da atividade. 


\section{EDUCAÇÃO, ARTES \\ VOLUME 11, NÚMERO 1, Ano 2015 \\ E INCLUSÃO \\ ISSN 1984-3178}

(2005), no ocidente "a tela tem uma função determinante na separação público e platéia e serve, principalmente para esconder os procedimentos do ator-animador. E no Oriente a tela é mais um muro translúcido que separa o lugar do cotidiano do lugar da magia”. Eu participei do jogo na roda junto com as crianças, também em interação no grupo com os materiais. Enquanto eu sustentava a lanterna iluminando a tela, orientava as crianças para sustentarem os fios da silhueta, de maneira que fosse possível visualizar melhor a sombra, para o grupo tentar adivinhar qual era a parte da história.

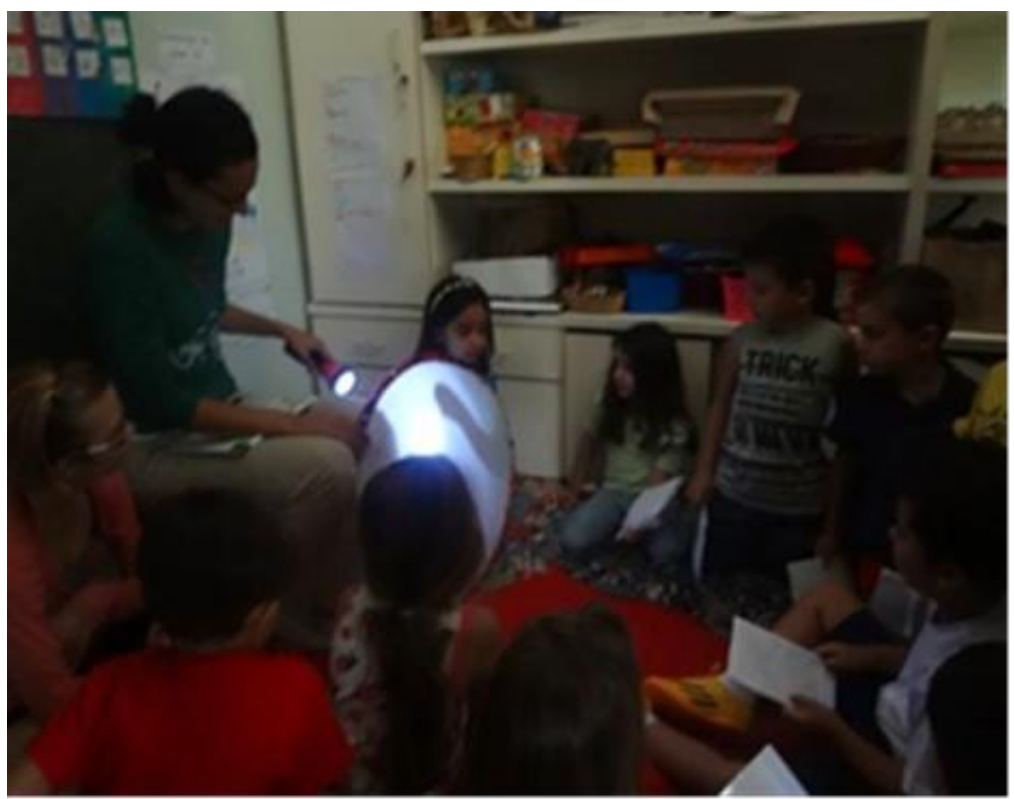

Figura 11 - Jogo em roda

Outras funções da tela móvel são exploradas por grupos ocidentais de teatro contemporâneos, que trabalham com a linguagem do teatro de sombras, conforme as observações de Beltrame (2005):

Mover a tela determina outras rupturas: provoca movimento na silhueta, ela se anima. Já não exige o virtuosismo do animador para manipular 10 varas simultaneamente como ocorre com o marionetista no Oriente. Cai a exigência da silhueta com diversas articulações e o movimento da tela possibilita a "deformação poética da imagem". Ou seja, o movimento da tela permite explorar formas e detalhes da imagem, ampliando o uso de recursos líricos e oníricos (BELTRAME, 2005, p.52)

Neste jogo com as crianças observei que a tela móvel enfatizou a interação no grupo, o jogo entre quem fazia a sombra aparecer e quem assistia. No entanto, penso que há diversas 


\section{EDUCAÇÃO, ARTES}

possibilidades de brincadeiras a serem exploradas com o uso de telas móveis em vivências com teatro de sombras.

Sobre o trabalho do ator no teatro de sombras, Beltrame (2005) comenta que "na atuação o olhar do intérprete deve controlar a imagem projetada na tela, a sombra; e o movimento da silhueta nem sempre condiz com o movimento da sombra/imagem" (p.53). Isto exige do ator, nesse caso da criança, a qualidade de absorção à atuação, que não visa a representação de alguém pela criança, mas a movimentação da sombra que é o personagem (ver Figura 12). O autor e pesquisador de teatro de animação Paulo Balardim (2004) afirma que "a vida no objeto inanimado, torna-se realidade perante os olhos do espectador", e observa que nos casos de teatro de sombras ou objeto-luzes "o personagem visto pelo público não se constitui em matéria palpável (corpo) e sim em uma impressão ótica causada à retina, registrada como uma forma ou sensação de cor" (BALARDIM, 2004, p.69).

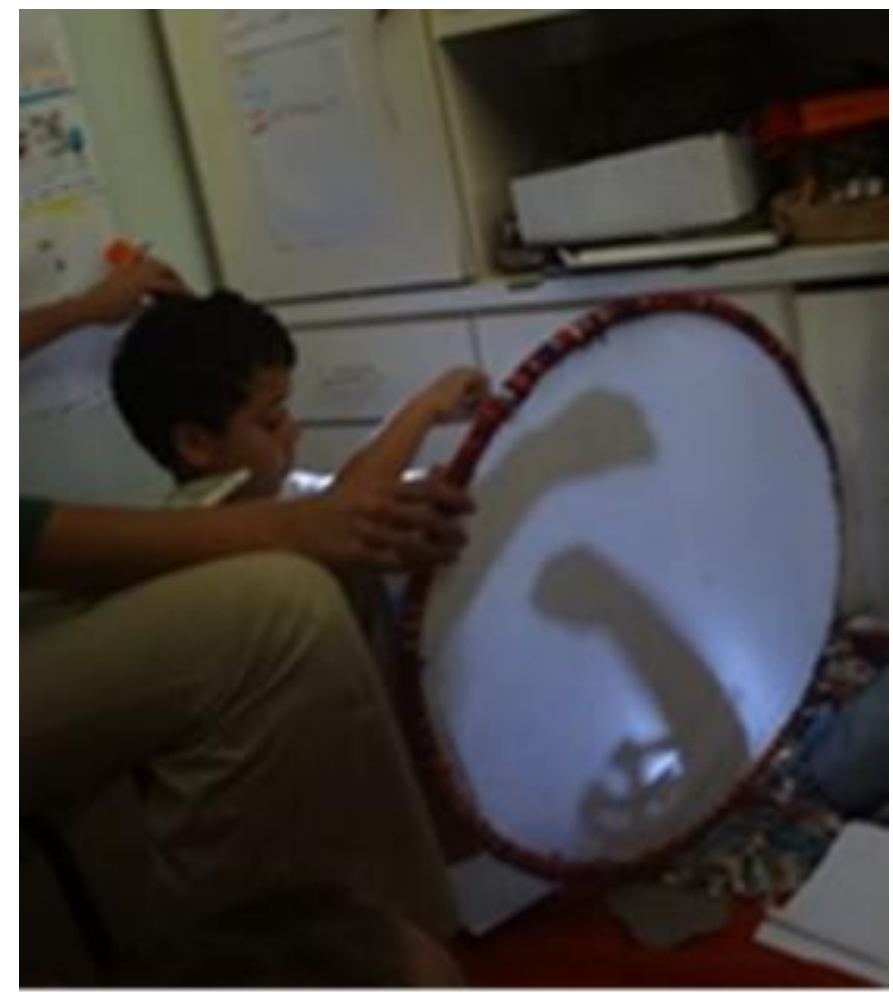

Figura 12 - Criança manipulando a silhueta

Segundo o autor "o teatro de animação existe enquanto houver, num mesmo espaço cênico e atuando ao mesmo tempo, na mesma representação, o corpo ou forma animada, o 
ator que lhe manipula e interpreta, e o público" (BALARDIM, 2004, p.69). Embora o jogo com as crianças não tenha sido organizado na disposição palco-platéia, tais elementos característicos do fazer teatro o constituíram.

\title{
Considerações
}

Devido o compromisso do PIBID com a formação docente, e à valorização das práticas de ensino na educação básica em consonância com o conhecimento produzido na Universidade, considero que este estudo foi muito importante. Nele, pude desenvolver reflexões ao aproximar o ensino da linguagem do teatro de sombras na educação infantil com o fazer teatro entendido pelo adulto, ampliando assim o olhar sobre as vivências em ensino de teatro com as crianças. Normalmente são desenvolvidas atividades com sombras na educação infantil, mas sem se considerar as especificidades teatrais das práticas, que são focadas em aspectos pedagógicos. No entanto, há aproximações entre as áreas que precisam ser revistas para que o ensino de teatro não se reduza a apresentação de uma história, sem se considerar a importância do processo de ensino nas relações entre o professor e crianças. Conforme o pensamento de Marcondes (2010):

\begin{abstract}
(...) distanciando-se dos estereótipos do que é bom para a criança pré-escolar, ou do que são conteúdo e forma próprios do infantil, e aproximando-se de uma abordagem antropológica para compreender como as crianças vivem sua vida, seus conflitos, suas dúvidas, suas criações, os professores das crianças de zero a seis anos poderão fazer surgir um espaço potencial de criação e troca entre ele e os alunos, entre o grupo de crianças, entre cada criança e o mundo compartilhado. Essa aproximação antropológica se dá em gesto e palavra, na medida em que os alunos são parte intrínseca de toda e qualquer performance vivida e/ou proposta por seu professor: momentos da convivência e da continuidade dos processos de conhecimento, nos quais o professor se faz performativo e comunica algo aos alunos, seja por meio de diferentes tipos de narrativas ou brincadeiras teatrais a serem experienciadas pelas crianças (MARCONDES, 2010, p.117)
\end{abstract}

Neste estudo, pude constatar que há muitas possibilidades a serem exploradas em experiências lúdicas com a linguagem do teatro de sombras no processo de ensino de teatro com crianças. A interação com os elementos: tela, luz e silhuetas criam situações de encontro e proximidade entre professor-criança e entre criança-criança, assim enfatizando mais a presença e comunicação nas relações no ensino, também sendo um espaço potencial de troca como sugere a autora no trecho citado acima. Devido a relação com o imaginário que as 


\title{
EDUCAÇÃO, ARTES
}

VOLUME 11, NÚMERO 1, Ano 2015 E INCLUSÃO

sombras evocam em quem faz e em quem assiste, considero que é uma linguagem não só a ser considerada como teatro para criança, mas para o adulto também. Balardim (2004) conclui que "o papel do ator-manipulador é catalisar o desejo do público em liberar o seu imaginário da concretude do plano físico.” (p.54) E ressalta que:

\begin{abstract}
"O artista criador faz com que as pessoas vejam o mundo de outra maneira, pois ele revela as faces da realidade, daquilo que nós percebemos pelos nossos sentidos, daquilo que temos consciência. Revela, também, os possíveis valores encontrados no mundo indizível, fazendo aflorar sentimentos conhecidos ou não através da ficção que propõem na obra de arte (...). O sentimento artístico está inserido na cultura, no conjunto das criações do homem e nos comportamentos apreendidos e transmitidos socialmente" (BALARDIM, 2004, p.53-54)
\end{abstract}

Assim, a imaginação é algo que une adulto e criança nas práticas artísticas.

\section{REFERÊNCIAS:}

BALARDIM, Paulo. Relações de vida e morte no teatro de animação. Porto Alegre: Ed do Autor, 2004.

BELTRAME, Valmor. Teatro de sombras: técnica e linguagem. Florianópolis: Ed. da UDESC, 2005.

BOURRIAUD, Nicolas. Estética relacional. São Paulo: Martins, 2009.

MACHADO, Marina Marcondes. A criança é performer. In: Revista Educação \& Realidade, v.35, $\mathrm{n}^{\circ} 2$. Porto Alegre, UFRGS, 2010. Disponível em http://seer.ufrgs.br/educacaoerealidade/article/view/11444 Acessado em 18/11/2013.

MACHADO, Marina Marcondes. Teatro, possíveis mundos de vida (e morte). In: Revista aSPAs, v.4, $\mathrm{n}^{\circ} 2$. São Paulo, USP, 2014. Disponível em http://www.revistas.usp.br/aspas/article/view/85291 Acessado em 11/01/2015.

SLADE, Peter. O jogo dramático infantil. São Paulo: Summus, 1978. 